\title{
In memoriam Atsushi Komamine
}

\author{
Jang R. Liu
}

Published online: 10 September 2011

(C) Korean Society for Plant Biotechnology and Springer 2011

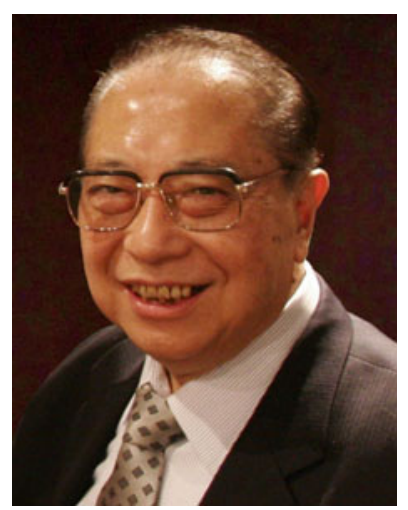

Plant Biotechnology Reports announces with deep sorrow that Professor Komamine, cofounder of this journal, passed away on July 6, 2011 at the age of 82. He was also President of the Asia-Pacific Association of Plant Tissue Culture and Agri-biotechnology, cohost of this journal.

Professor Komamine was none other than a good colleague and friend to members of the Association as well

as an admirable teacher. He was a pioneer of plant biotechnology in Japan and one of the most prominent figures in the international plant science community. Many scientists in the community have respected his efforts and enthusiasm in organizing scientists across the world and also his scientific achievements.

In the obituary published in this issue, Professor Hiroaki Kodama describes Professor Komamine's major scientific achievements and his life as a role model for young scientists. Professor Komamine was a man of challenge and youth. He was in advance of his time. I am sure that he will be more appreciated from now on than he may have been in the past. Professor Komamine will be remembered as a legend in our days.

Jang R. Liu

Editor-in-Chief

J. R. Liu $(\bowtie)$

Korea Research Institute of Bioscience and Biotechnology (KRIBB), 52 Eoeun-dong, Yuseong-gu, Daejeon 305-333, Korea

e-mail: jrliu@kribb.re.kr 